\title{
O USO DOS PRONOMES “NÓS” E “WE” E A CONSTRUÇÃO DE IDENTIDADES COLETIVAS NO CORPUS PARALELO GRANDE SERTÃO: VEREDAS || THE DEVIL TO PAY IN THE BACKLANDS
}

\author{
THE PRONOUNS 'NÓS' AND 'WE' AND THE CONSTRUAL OF COLLECTIVE \\ IDENTITIES ON THE PARALLEL CORPUS GRANDE SERTÃO: VEREDAS \| THE \\ DEVIL TO PAY IN THE BACKLANDS
}

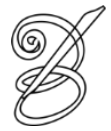 \\ Cristiane Bezerra do NASCIMENTO ${ }^{1}$ \\ Universidade Federal da Paraíba \\ Daniel ALVES ${ }^{2}$ \\ Universidade Federal da Paraíba
}

\begin{abstract}
Resumo: O presente artigo tem por objetivo apresentar uma análise dos usos dos pronomes pessoais "nós" e "we" em um corpus paralelo ficcional, composto pelos textos Grande Sertão: Veredas, de Guimarães Rosa, e sua única tradução para o inglês, The devil to pay in the backlands, de James L. Taylor e Harriet de Onís. A investigação busca entender como os pronomes são usados quando os contextos nos quais eles estão colocados implicam a construção de situações de conflito armado. $\mathrm{O}$ artigo busca dialogar com pesquisas que investigam o uso dos pronomes pessoais como Barbara e Gouveia (2004) e Maia (1998), e também estabelecer diálogos com trabalhos que tratam da construção de identidades e de conflito como Leudar, Marsland e Nekvapil (2004) e Brewer (2011). Metodologicamente, foi utilizada a ferramenta software AntConc, com vistas a realizar trabalhos de levantamento e filtragem de dados para a pesquisa. Dentre os resultados, destacam-se a frequência de elisão do pronome "nós" em português $(88,7 \%$ dos casos levantados a partir do corpus são de usos elípticos, contra $11,3 \%$ de usos explícitos); destaca-se também o uso explícito, e anteposto ao verbo, do pronome "we", em língua inglesa ( $96 \%$ das linhas analisadas se encaixam nessa situação) - o que condiz com a estrutura esperada para a língua inglesa. No que diz respeito à construção de identidades coletivas, os dados contrariam as expectativas iniciais da pesquisa, não sendo unânimes os usos em referência aos grupos aliados, tampouco as associações esperadas de prosódias semânticas positivas construindo os grupos identificados como aliados.
\end{abstract}

Palavras-chave: Linguística de Corpus. Tradução e Conflito. Grande Sertão: Veredas - The devil to pay in the backlands. Pronomes pessoais "nós" e "we".

\begin{abstract}
This paper aims at presenting an analysis of the pronouns 'nós' and 'we' on the parallel fictional corpus Grande Sertão: Veredas, by Guimarães Rosa, and The devil to pay in the backlands, by James L. Taylor and Harriet de Onis. The analysis focuses on the uses of the pronouns in contexts of an armed conflict fought by disputing groups. This paper draws on the explorations on the uses of pronouns in Portuguese and in English such as Barbara and Gouveia (2004) and Maia (1998) - and on discussions on the construal of conflicts and collective identities - such as Leudar, Marsland and Nekvapil (2004) and Brewer (2011). Methodologically, the AntConc software was used for data collection and selection of lines for analysis. Some of the main findings for this investigation point to a tendency of ellipsis of the pronoun 'nós' in Portuguese (88.7\% of the cases), and to the explicit use of the pronoun 'we' in English in ante position to the verb (96\% of these cases) - as expected, considering the structure of the English language. Regarding the construal of collective identities, the results point to non-rigid settings of the groups, but to fluid constructions of social groups, which translates in neutral or even negative semantic prosodies to the pronouns 'nós' and 'we' and to the groups they represent as allies.
\end{abstract}

NASCIMENTO, ALVES. O uso dos pronomes "nós" e "we" e a construção de identidades coletivas no corpus paralelo Grande Sertão: Veredas || The Devil to Pay in the Backlands.

Belas Infiéis, v. 6, n. 1, p. 43-64, 2017. 
Key-Words: Corpus Linguistics. Translation and Conflict. Grande Sertão: Veredas - The devil to pay in the backlands. Personal pronouns 'nós' and 'we'.

\section{Introdução}

$O$ presente artigo apresenta um recorte da pesquisa de iniciação científica "O uso de pronomes pessoais 'nós' e 'eles' e a construção de identidades coletivas no corpus paralelo Grande Sertão: Veredas || The devil to pay in the backlands", desenvolvida graças ao apoio da Universidade Federal da Paraíba. A pesquisa se insere no campo disciplinar dos Estudos da Tradução e busca, com o aporte da Linguística de Corpus, analisar os usos dos pronomes pessoais "nós" e "we", respectivamente na língua portuguesa e na língua inglesa, a partir do corpus paralelo bilíngue (não alinhado) constituído pelo romance Grande Sertão: Veredas, escrito por Guimarães Rosa, e por sua única tradução para o inglês, até a presente data, The devil to pay in the backlands, de James L. Taylor e Harriet de Onís.

O artigo visa inicialmente a contribuir para a compreensão dos usos pronomes pessoais "nós" e "we" quando colocados em relação tradutória. Ao buscar essa compreensão por meio de uma investigação realizada em um corpus paralelo ficcional, este trabalho parte do entendimento de que textos podem revelar aspectos sobre os sistemas linguísticos no quais eles se inserem, funcionando como janelas que permitem visualizar o sistema linguístico acompanhando a metáfora utilizada por Halliday e Matthiessen (2004) ao discutirem as possibilidades de focos para pesquisas linguísticas. Além de buscar compreender os usos de pronomes pessoais, este trabalho também visa à compreensão de processos de construção de identidades coletivas, em contextos de conflito entre grupos armados, analisando, para tanto, não apenas os usos dos pronomes pessoais "nós" e "we", como também as dêixis, os contextos de uso e as prosódias semânticas desses pronomes.

Para o seu desenvolvimento, este trabalho conta com os aportes teóricos de Maia (1998) - que investiga os usos dos pronomes pessoais "eu", na língua portuguesa, e " $I$ ", na língua inglesa -, de Babara e Gouveia (2010) - que investigam o uso dos pronomes pessoais em português brasileiro - e de Bar-Tal (2011), Brewer (2011), Leudar, Marslande e Nekvapil (2004) - que discutem a construção de identidades coletivas, os processos de contraposição de grupos sociais (em construções "nós" versus "eles") e as relações de conflitos entre grupos sociais. 
A pesquisa aqui apresentada se apoia em um desenho metodológico da Linguística de Corpus, empregando o software AntConc (ANTHONY, 2011) - uma ferramenta de processamento de corpus, disponível gratuitamente na internet - para levantar dados relativos aos pronomes "nós" e "we" no corpus, classificando-os a partir das posições (anteposta ou posposta) do pronome, da realização explícita e desinencial e da dêixis, além de se observarem outros padrões de linguagem a partir de explorações do corpus.

Para realizar a proposta delineada nesta introdução, este artigo está organizado em quatro seções. A seção 2 faz uma breve revisão teórica, abrangendo pesquisas que investigam os usos de pronomes em português e em inglês e discussões sobre relações de conflito e investigações de conflitos por meio da linguagem. A seção 3 apresenta o corpus investigado e o método de pesquisa, apresentando informações contextuais sobre o corpus e sobre os procedimentos adotados para levantamento de dados por meio do software AntConc e análise desses dados. A seção 4 apresenta a análise de dados e a discussão, discorrendo sobre o trabalho de classificação aqui realizado, sobre os usos dos pronomes "nós" e "we" e trazendo interpretações possíveis a partir dos dados levantados. Por fim, a última seção apresenta as considerações finais do trabalho, retomando possíveis leituras dos dados e fazendo indicações de futuros desenvolvimentos.

\section{Revisão Teórica}

Como mencionado na introdução deste artigo, esta pesquisa parte da investigação dos usos dos pronomes pessoais "nós", em língua portuguesa, e "we", em língua inglesa, e, a partir deles, busca compreender os processos de construção de identidades coletivas realizados no corpus pesquisado. Fundamentais para essa proposta são os trabalhos de Maia (1998) e de Barbara e Gouveia (2004) - ambas sobre o uso de pronomes pessoais.

NASCIMENTO, ALVES. O uso dos pronomes "nós" e "we" e a construção de identidades coletivas no corpus paralelo Grande Sertão: Veredas || The Devil to Pay in the Backlands.

Belas Infiéis, v. 6, n. 1, p. 43-64, 2017. 
Trabalhando com um corpus paralelo comparável, composto por textos ficcionais, Maia (1998) investiga os usos dos pronomes de primeira pessoa (“eu" e " $P$ "), analisando questões como posição (anteposta ou posposta) do pronome, realização explícita e elisão do pronome. A partir de sua investigação, Maia (1998) observa a elisão do pronome "eu" como sendo frequente em textos originalmente escritos em português e menos frequente em textos traduzidos do inglês para o português - o que pode ser, segundo a autora, um indício da interferência da língua fonte na tradução (considerando que a língua inglesa oferece menos recursos de elisão pronominal do que a língua portuguesa). A partir de seus dados, Maia (1998) também chama a atenção para o fato de que nem todas as formas verbais em português são claramente marcadas (havendo coincidência de desinências para a primeira e a terceira pessoas do singular em tempos como Pretérito Imperfeito, Futuro do Pretérito e algumas formas de infinitivo) e observa os usos explícitos de "eu" como recurso de desambiguação apontando que o pronome "eu" é mais frequentemente utilizado como desambiguador em textos traduzidos para o português $(43,8 \%$ dos casos) do que em textos originalmente escritos em português $(40,2 \%$ dos casos).

Barbara e Gouveia (2004) também investigam usos explícitos e elípticos dos pronomes pessoais em português. Analisando fragmentos de textos literários e adotando a Gramática Sistêmico-Funcional (e textos correlatos) como referencial teórico, os autores investigam as funções coesivas de Referência e Elipse dos pronomes em língua portuguesa, concluindo que, em língua portuguesa, a elisão de pronomes pessoais (com função de sujeito oracional) não traz prejuízos à construção de cadeias coesivas.

Seguindo as linhas de pesquisa de Maia (1998) e de Barbara e Gouveia (2004), a pesquisa aqui apresentada investiga os usos de pronomes pessoais em português e inglês, mas concentrando-se nos usos dos pronomes "nós" e "we", como forma de entender os processos de construção de identidades coletivas em grupos sociais. Para tanto, a pesquisa adota ferramentas da Linguística de Corpus para orientar o trabalho de levantamento de dados e se afilia, dessa forma, a um ramo da linguística que vem sendo desenvolvido desde a década de 1960 e que se caracteriza pela busca de padrões de linguagem a partir de textos em formato eletrônico, com o auxílio de softwares especializados - que permitem a identificação de padrões de usos da linguagem muitas vezes não perceptíveis por outros meios da análise. 
Ao centrar a análise aqui apresentada nos usos dos pronomes "nós" e "we", esta proposta busca entender, sob uma perspectiva sintático-semântica, o papel da linguagem enquanto sistema construtor/modelador da realidade. Entendemos os pronomes "nós" e "we" como indicativos do estabelecimento de coesão entre um grupo social - coesão a partir da qual diferentes indivíduos passam a se identificar como uma unidade coletiva reconhecida sob o epíteto "nós". Ao propor a investigação linguística desse processo de construção de identidade coletiva, esta investigação se alinha a propostas de compreensão de conflitos por meio de análises linguísticas - como Butt, Lukin e Matthiessen (2004), por exemplo, que mostram, a partir de dois discursos políticos (o primeiro do então presidente dos Estados Unidos, George W. Bush, e o segundo do Tenente Coronel Tim Collins na véspera da invasão do Iraque), como recursos retóricos e linguísticos podem ser utilizados para construir uma contraposição entre as noções de nós versus eles $^{3}$ (enquanto grupos sociais) e, com isso, criar condições sociais para um confrontamento bélico.

Embora possa nem sempre ser aparente a relação entre a importância da investigação linguística e a compreensão de conflitos entre grupos sociais, trata-se de uma relação importante para esta investigação. Segundo Butt, Lukin e Matthiessen (2004), o primeiro instrumento empregado em guerras - e em outras experiências de conflito - é de natureza linguística: para os autores, são de natureza linguística as ações que precedem processos de enfrentamento - como, por exemplo, a definição de quem é o ente inimigo, o uso de recursos textuais (retóricos e discursivos) para convencer a sociedade sobre a necessidade de atacar o tal inimigo e assim por diante.

Para fins desta pesquisa, conflito é entendido como um fenômeno de natureza cotidiana - observável nas diversas esferas e agrupamentos sociais (desde o casal até os grandes agrupamentos políticos) -, essencial para a formação e manutenção de grupos sociais (BIRNBAUM,1995), que ocorre quando duas ou mais partes buscam se enfraquecer mutuamente "por terem objetivos incompatíveis, interesses contrários ou valores fundamentalmente diferentes" (BAKER, 2006, p.1-2). Embora a definição seja breve, cumpre também destacar a complexidade de conflitos enquanto fenômenos sociais - o que se deve, segundo Bar-Tal (2012), ao fato de sua construção ser influenciada por três estruturas sócio psicológicas: a) as memórias coletivas relacionadas das partes envolvidas acerca dos aspectos que caracterizam o conflito; b) as orientações emocionais das partes em relação uma à outra; e c) o caráter moral (ethos) do conflito em si.

NASCIMENTO, ALVES. O uso dos pronomes "nós" e "we" e a construção de identidades coletivas no corpus paralelo Grande Sertão: Veredas || The Devil to Pay in the Backlands.

Belas Infiéis, v. 6, n. 1, p. 43-64, 2017. 
Assim, ao investigar os processos de criação de identidades coletivas por meio dos usos dos pronomes "nós" e "we", esta pesquisa também busca dialogar com as propostas de Birnbaum (1995), entendendo o conflito como elemento formador de grupos sociais, e de BarTal (2012) ao buscar compreender os mecanismos de construção da memória coletiva das partes envolvidas - investigando as formas como os membros das sociedades conflitantes se representam enquanto grupo social e os recursos textuais e discursivos empregados para construir padrões sociais, comportamentos políticos e representações ideologicamente orientadas.

Uma das vantagens em adotar uma metodologia ligada à Linguística de Corpus para a investigação aqui apresentada está nas possibilidades que tal ramo da linguística oferece para a identificação de padrões e de características textuais não facilmente perceptíveis por meio da observação (ou da intuição) humana pura, como apontam Silva, Vasconcellos e Fernandes (2009). Um exemplo dessas possibilidades é a investigação das prosódias semânticas de itens lexicais, que consiste, como apontam os autores, na atribuição de atitudes e avaliações a itens lexicais, devido à proximidade ou à repetição consistente desses itens com outros itens

48 lexicais (positivos, negativos ou neutros) em determinadas situações pragmáticas. Tal investigação é amplamente facilitada pelo uso de ferramentas de corpora, especialmente graças às possibilidades que elas abrem para o levantamento sistemático de dados linguísticos. Após discutir os principais trabalhos e conceitos a serem utilizados neste trabalho, a próxima seção passa a apresentar os textos que compõem o corpus desta pesquisa e o método empregado para levantamento e análise de dados.

\section{Corpus e método de pesquisa}

Como anunciado na introdução deste texto, a investigação aqui apresentada foi realizada com base no corpus paralelo bilíngue, não alinhado, composto pelos romances Grande Sertão: Veredas e The devil to pay in the backlands. Os dados do corpus foram levantados por meio da ferramenta AntConc, visando a compreender os usos dos pronomes "nós" e "we", inicialmente analisados acompanhando a proposta de Maia (1998).

NASCIMENTO, ALVES. O uso dos pronomes "nós" e "we" e a construção de identidades coletivas no corpus paralelo Grande Sertão: Veredas || The Devil to Pay in the Backlands.

Belas Infiéis, v. 6, n. 1, p. 43-64, 2017. 
O primeiro texto analisado foi Grande Sertão: Veredas. Escrito por Guimarães Rosa, publicado pela primeira vez em 1956 e reeditado no ano de 1958, o texto faz parte do cânone brasileiro, sendo uma das mais importantes obras do escritor. Caracterizado, assim como outros romances do modernismo que começaram a ser escritos em 1930, pelo uso marcado de expressões linguísticas regionais, Grande Sertão: Veredas apresenta uma narrativa com características de oralidade, não seguindo uma forma linear e construindo, sem divisões de capítulos, a narrativa do ex-jagunço Riobaldo (também conhecido como Tatarana ou UrutuBranco ao longo da história), narrador e protagonista do livro. No texto, Riobaldo tece a história de sua vida, narrando como decidiu se tornar jagunço, seu amor impossível pelo também jagunço Reinaldo/Diadorim e seus questionamentos espirituais.

O segundo texto que compõe o corpus analisado é a tradução The devil to pay in the backlands, por James L. Taylor e Harriet de Onís. Publicada em 1963, a tradução é - como aponta Alves (2014) - a primeira, e até hoje única, tradução de Grande Sertão: Veredas publicada em língua inglesa, tendo grande importância para a divulgação internacional do texto de Guimarães Rosa - embora seja frequentemente criticada por não explorar recursos da criatividade lexical de forma análoga à feita no original, como apontam Vasconcelos (2009), Alves (2014) e Pedrosa (2009), para citar alguns. Pedrosa (2009), por exemplo, chega a mencionar que os tradutores preferiram trabalhar com uma linguagem mais formal, de modo que o texto alvo não apresenta várias das marcas características do texto fonte.

Tendo apresentado o corpus de estudo, passaremos a discutir o desenho de pesquisa adotado na investigação aqui apresentada. Na próxima seção serão apresentadas as etapas para a investigação de cada componente do corpus tais como: a) o software utilizado para a coleta de dados; b) os métodos empregados no levantamento de dados; e c) as categorias de análise das linhas de concordância analisadas tanto na língua inglesa como na língua portuguesa.

NASCIMENTO, ALVES. O uso dos pronomes "nós" e "we" e a construção de identidades coletivas no corpus paralelo Grande Sertão: Veredas || The Devil to Pay in the Backlands.

Belas Infiéis, v. 6, n. 1, p. 43-64, 2017. 


\subsection{Desenho de pesquisa}

Como visto anteriormente, o estudo aqui apresentado teve por objetivo analisar o uso dos pronomes pessoal "nós" e "we" em um corpus paralelo ficcional, visando a compreender tanto os usos dos pronomes quanto a forma como eles são usados para construir identidades coletivas em um contexto de conflito armado. Para tanto, os textos que compõem o corpus foram processados por meio do software AntConc (ANTHONY, 2011) - uma ferramenta gratuita que permite fazer buscas e análises a partir de corpora. A escolha do AntConc se justifica por sua versatilidade e por sua disponibilidade gratuita, adequada ao contexto de uma universidade pública.

As linhas de concordância a serem analisadas em língua portuguesa foram levantadas a partir das desinências verbais associadas ao pronome pessoal "nós". Essa decisão (em utilizar desinências verbais como nódulo de busca) se justifica pelo interesse em analisar tanto as construções que fazem uso explícito quanto as que fazem uso elíptico/desinencial do pronome. Partindo da compreensão de Azeredo (2000, p.71) de que "desinência é o morfema gramatical que se coloca após o tema do vocábulo para indicar suas variações morfossintáticas", foram levantadas todas as terminações associadas ao pronome "nós" encontradas em Grande Sertão: Veredas. Utilizando a função de levantamento por terminações de palavras (regex) da ferramenta Concordance do AntConc (exemplificada na Figura 1, a seguir), foram levantadas linhas de concordância a partir das buscas pelas desinências "-amos", “-emos", “-imos", “-omos", “-armos”, “-ermos”, “-irmos” e “-ormos” para todas as conjugações temporais. Em uma pesquisa detalhada, o software AntConc apontou um número de 795 desinências para serem filtradas e analisadas posteriormente.

NASCIMENTO, ALVES. O uso dos pronomes "nós" e "we" e a construção de identidades coletivas no corpus paralelo Grande Sertão: Veredas || The Devil to Pay in the Backlands.

Belas Infiéis, v. 6, n. 1, p. 43-64, 2017. 
Figura 1 - Tela do AntConc: levantamento de linhas de concordância a partir das desinências verbais do pronome nós, utilizando a função Regex.

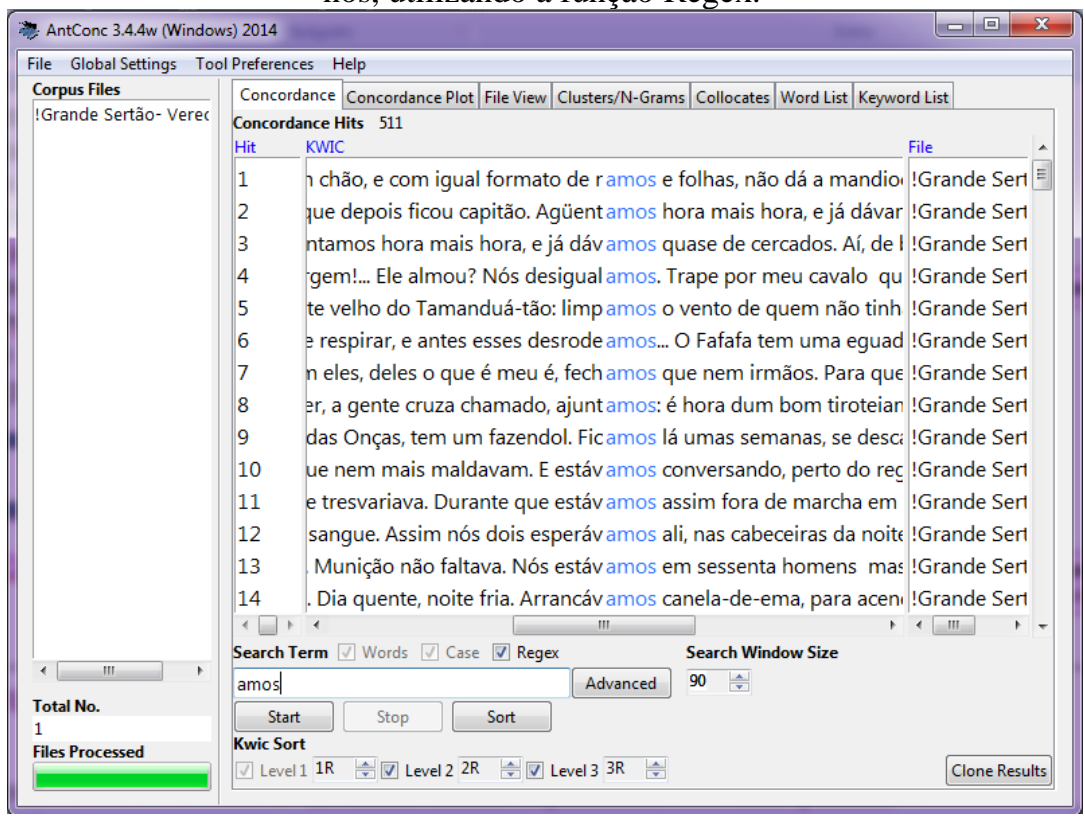

Como anteriormente apontado, a Figura 1, acima, mostra o levantamento de linhas de concordância pela opção Regex (de terminações de palavras) do AntConc. Na imagem, é possível ver o levantamento de 511 linhas de concordância a partir da desinência "-amos" quando consideradas todas as demais desinências verbais, o total de linhas de concordância chega a 795 .

Após o levantamento, os dados foram organizados em uma planilha eletrônica do Microsoft Excel, de forma a facilitar os trabalhos de classificação e contagem de dados, seguindo a proposta de Alves e Assis (2016). A planilha foi organizada de modo a permitir a classificação dos dados quanto à realização do pronome (explícita ou desinencial), à posição pronominal (anteposta ou posposta) e à identificação dos dêiticos (pela explicitação de a quais grupos os dêiticos pessoais "nós" se referem em cada instância levantada). O Quadro 1, a seguir, exemplifica a organização da planilha:

Quadro 1 - Exemplo de classificação dos dados em português

\begin{tabular}{|c|c|c|c|c|}
\hline Linha de concordância & $\begin{array}{c}\text { Realização do } \\
\text { pronome }\end{array}$ & $\begin{array}{c}\text { Posição } \\
\text { pronominal }\end{array}$ & $\begin{array}{c}\text { Identificação } \\
\text { (dêitico) }\end{array}$ & $\begin{array}{c}\begin{array}{c}\text { Prosódia } \\
\text { semântica }\end{array} \\
\end{array}$ \\
\hline $\begin{array}{l}\text { Deu um galope, em } \\
\text { encontro. Nós todos, de } \\
\text { começo, ficamos } \\
\text { atarantados. }\end{array}$ & Explícito & Anteposto & $\begin{array}{l}\text { Grupo de } \\
\text { jagunços de } \\
\text { Joca Ramiro }\end{array}$ & $\begin{array}{l}\text { Negativa } \\
\text { (indica } \\
\text { confusão/desnor } \\
\text { teamento do } \\
\text { grupo) }\end{array}$ \\
\hline
\end{tabular}

NASCIMENTO, ALVES. O uso dos pronomes "nós" e "we" e a construção de identidades coletivas no corpus paralelo Grande Sertão: Veredas || The Devil to Pay in the Backlands.

Belas Infiéis, v. 6, n. 1, p. 43-64, 2017. 
O Quadro 1 exemplifica a classificação dos dados levantados para a investigação do pronome "nós", conforme anteriormente descrito. No quadro, são apresentadas as colunas reservadas para as classificações das desinências verbais (no exemplo dado, levantado pela desinência "amos", destacada em "ficamos"), realização dos pronomes, posição pronominal, análise dos dêiticos e prosódia semântica.

Respeitando as características individuais de cada língua componente do corpus, foi adotado um método diferente para o levantamento de dados em língua inglesa. Considerando que - diferentemente do português - a língua inglesa não oferece recursos de elisão pronominal, o levantamento de dados foi baseado no nódulo "we", utilizando a função de levantamento de linhas de concordância a partir de palavras inteiras (words) da ferramenta Concordance do AntConc, como mostra a Figura 2, a seguir:

Figura 2 - Tela do AntConc: levantamento de linhas de concordância do pronome "we" a partir da função Words

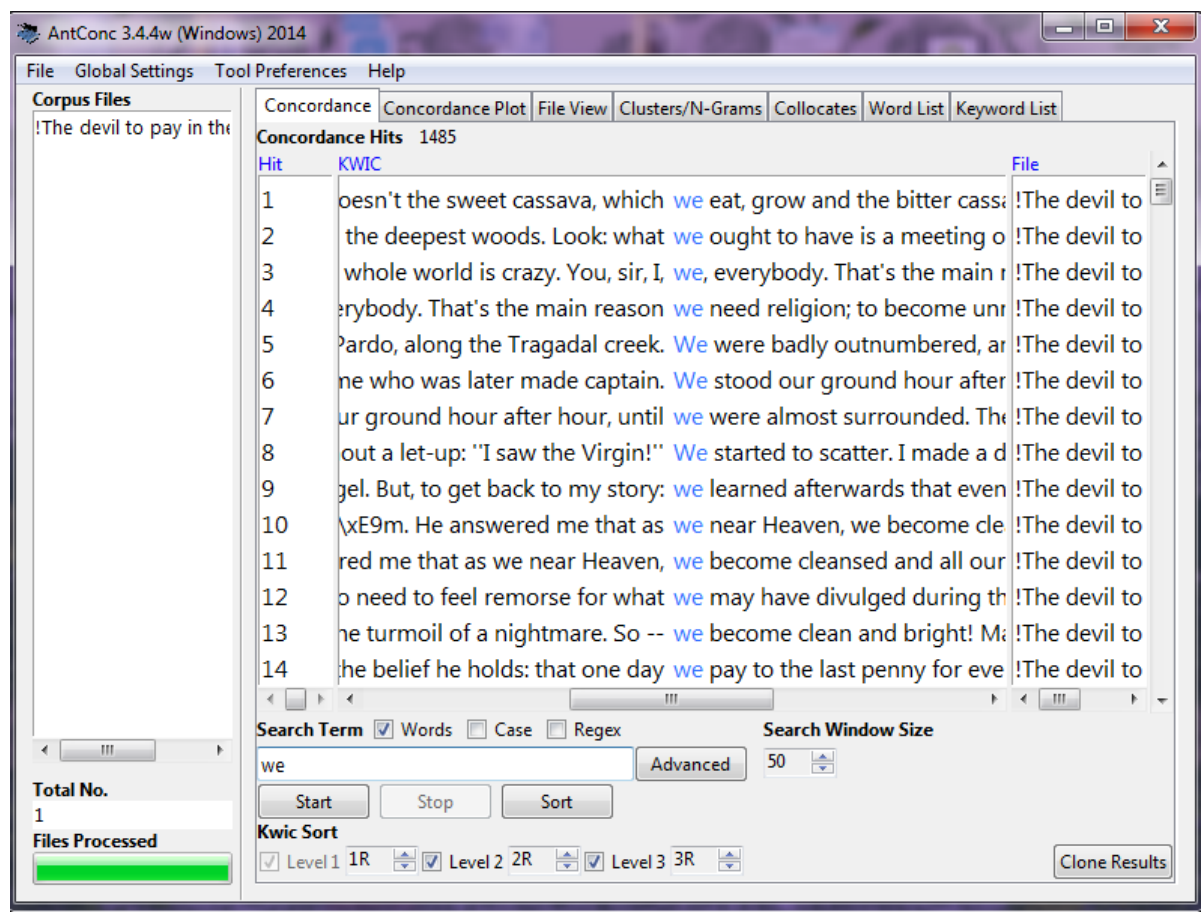

Como anteriormente mencionado, a Figura 2, acima, mostra o levantamento de linhas de concordância pela opção Words (de palavras inteiras) do AntConc. Na imagem, é possível ver o levantamento de 1.484 linhas de concordância a partir do nódulo "we". 
Assim como nos dados em português, os resultados foram organizados em uma planilha eletrônica do Microsoft Excel, organizada de modo a permitir a classificação quanto à posição pronominal (anteposta ou posposta) e à identificação dos dêiticos (a quais grupos se referem as instâncias de "nós" levantadas) e à prosódia semântica (positiva, negativa ou neutra) que a linha de concordância associa aos grupos identificados. O Quadro 2, a seguir, exemplifica a organização da planilha:

Quadro 2 - Exemplo de classificação dos dados em inglês

\begin{tabular}{c|c|c|c}
\multicolumn{1}{c|}{ Linha de concordância } & $\begin{array}{c}\text { Posição } \\
\text { pronominal }\end{array}$ & $\begin{array}{c}\text { Identificação } \\
\text { (dêitico) }\end{array}$ & $\begin{array}{c}\text { Prosódia } \\
\text { semântica }\end{array}$ \\
\hline "I saw the Virgin!" We started to & Anteposto & $\begin{array}{c}\text { Grupo de } \\
\text { jagunços de Joca } \\
\text { Ramiro }\end{array}$ & $\begin{array}{l}\text { Negativa (indica } \\
\text { dispersão do } \\
\text { grupo) }\end{array}$
\end{tabular}

O Quadro 2 exemplifica a classificação dos dados levantados para a investigação do pronome "we", conforme anteriormente descrito. No quadro, estão apresentadas as colunas reservadas para as classificações da posição pronominal, a identificação dos dêiticos e a valoração construída na oração.

Concluídos os procedimentos de classificação, os dados resultantes foram analisados, visando a estabelecer diálogos com os trabalhos de Maia (1998) e suas observações sobre a sintaxe da língua portuguesa e a ordem SVO - sujeito, verbo, objeto -; de Brewer (2011) e suas observações sobre a perspectiva psicológica social de grupos de conflito; e de Leudar, Marsland e Nekvapil (2004) sobre a relação entre membros de grupos sociais e ações violentas a partir de um discurso político.

A seção a seguir apresenta os resultados e discussões do presente trabalho, desde o levantamento de dados relativos aos usos dos pronomes "nós" e "we" até os diálogos com os trabalhos de Maia (1998), Brewer (2011) e Leudar, Marsland e Nekvapil (2004). 


\section{Análise de dados e discussões}

\subsection{Sobre os usos dos pronomes "nós" e "we"}

Seguindo os procedimentos descritos na seção anterior, inicialmente foram levantados os dados a serem analisados a partir do corpus em português. Utilizando-se o software AntConc, foram levantadas as linhas de concordância das palavras com as desinências verbais “-amos", “-emos", “-imos", “-omos”, “-armos”, “-ermos”, “-irmos”, “-ormos” para todas as conjugações temporais. Os resultados desse processo de levantamento estão organizados, a partir das desinências, na Tabela 1, a seguir:

Tabela 1 - Total de linhas de concordância levantadas, organizadas pelas desinências investigadas para o pronome "nós"

\begin{tabular}{c|c} 
Desinências verbais & Número de casos encontrados \\
\hline -amos & 511 \\
\hline- -emos & 186 \\
\hline -imos & 46 \\
\hline -omos & 39 \\
\hline -armos & 3 \\
\hline -ermos & 10 \\
\hline -irmos & 3 \\
\hline -ormos & 0 \\
\hline TOTAL & 798
\end{tabular}

A Tabela 1, acima, mostra o total de linhas de concordância levantadas a partir de cada busca por desinência verbal (associada ao pronome "nós"). Dentre os resultados, a desinência mais recorrente foi a de "-amos", com 511 resultados. Essas linhas de concordância foram conferidas, uma a uma, buscando confirmar se as terminações de palavras coincidiam com os usos de verbos flexionados ou não. Do total de 798 linhas analisadas, 758 (94,7\% do total analisado) eram verbos - resultados que indicam a adequação do método de levantamento de dados para a análise a que a pesquisa se propõe.

Embora adequado, o método também levantou alguns casos problemáticos - por exemplo, aqueles nos quais a noção do nós (enquanto grupo social) é construída por meio do grupo nominal "a gente", conforme mostram os exemplos a seguir:

Ex. 1. "só uns vinte mil-réis..." A gente muito rimos todos. A hora a ser de satisfa, alegrias

Ex. 2. Chamou. Falou misturado... A gente viemos." - "E o que é que falou?"

Ex. 3. Agora, com perdão vosso, a gente esquecemos, a gente gastou o entendido... 
Os exemplos 1, 2 e 3, acima, mostram casos problemáticos em que a noção de nós (enquanto grupo social) é construída por meio do grupo nominal a gente. Ao todo, foram encontrados 12 casos em que tal sintagma é utilizado como sujeito de uma forma verbal que apresenta uma flexão associada à primeira pessoa do plural. Dentre as possíveis soluções, foi adotada uma postura mais compreensiva da linguagem - em detrimento de uma postura associada à gramática normativa, que tende a não aceitar tais usos - e os usos de "a gente" foram analisados como formas de construir a noção de nós (grupo social) no discurso. A decisão se justifica pelo corpus, caracterizado pelo uso de expressões linguísticas regionais e um registro associável à oralidade - além de ser uma linguagem imortalizada em um cânone literário.

Seguindo os passos delineados na seção anterior, sobre o método de investigação, o primeiro ponto observado a partir dos dados em português foram os usos elípticos e explícitos do pronome "nós". Os resultados dessa classificação estão apresentados na Tabela 2, a seguir:

Tabela 2 - Resultados da classificação quanto à realização (explícita ou elidida) do pronome "nós"

\begin{tabular}{c|c|c} 
Elíptico & 638 & $88,7 \%$ \\
\hline Explícito & 82 & $11,3 \%$ \\
\hline TOTAL & 720 & $100,0 \%$
\end{tabular}

A Tabela 2 mostra o resultado das classificações sobre os usos explícitos e elípticos do pronome "nós". A partir dos dados, observa-se que o texto em português tende a construir a primeira pessoa do plural por meio de verbos flexionados e elisão de pronomes: $87,7 \%$ das linhas de concordância analisadas não apresentam o pronome de forma explícita (contra $11,3 \%$ em que o pronome é explicitamente realizado). O resultado corrobora uma das expectativas iniciais da pesquisa - também corroborando a decisão de levantar as linhas de concordância a partir das desinências verbais (em detrimento do levantamento pelos usos explícitos do pronome).

NASCIMENTO, ALVES. O uso dos pronomes "nós" e "we" e a construção de identidades coletivas no corpus paralelo Grande Sertão: Veredas || The Devil to Pay in the Backlands.

Belas Infiéis, v. 6, n. 1, p. 43-64, 2017. 
A tendência à elisão pronominal, verificada nos dados aqui analisados, coincide com as observações de Barbara e Gouveia (2004), que apontam que, na língua portuguesa, a elisão de pronomes pessoais não traz prejuízos à construção de cadeias coesivas, sendo o seu uso mais uma questão de escolha e estilo do que de estrutura - ao contrário do que se observa em língua inglesa. Acompanhando Barbara e Gouveia (2004), é possível destacar que a predileção pelo uso elíptico do pronome no corpus Grande Sertão: Veredas pode ser relacionada ao estilo do texto, não operando dificuldades de compreensão em relação ao sentido e função, podendo ser entendido como uma forma de não repetir o sujeito (facilmente identificável pela desinência verbal).

Dentre os casos observados quando da classificação dos usos explícitos e elípticos dos pronomes, um caso interessante foi o da duplicidade pronominal, mostrado no exemplo a seguir:

Ex. 4. Ah, tempo de partida! A gente, nós, vamos é rente por essa cava, Riobaldo, meu filho.

O Exemplo 4, acima, mostra um caso em que tanto o sintagma "a gente" quanto o pronome "nós" são associados à forma verbal "vamos". No caso, ambos podem ser entendidos como sujeito oracional. Embora gramáticas normativas não prevejam o sintagma “a gente" como sujeito associável a desinências da primeira pessoa do plural, reiteramos aqui a opção por adotar uma abordagem mais compreensiva da língua portuguesa e considerá-lo, tanto quanto o pronome "nós", como sujeito de formas verbais com desinência em "-amos", “-emos", “-imos", “-omos”, etc.

Quanto à investigação dos usos dos pronomes "we" no corpus, como apontado na seção 3 (do método) deste trabalho, devido à estrutura da língua inglesa, o levantamento de dados no corpus em inglês se deu não pelas desinências verbais, mas pelos usos explícitos do pronome "we". Portanto, neste momento, uma comparação entre os dados em português relacionados à elipse do pronome "nós" e os dados em inglês quanto aos usos de "we".

Retomando a apresentação da classificação dos usos do pronome "nós", foram verificadas as tendências de colocação pronominal. Para tanto, foram analisados apenas os casos em que o pronome se encontra explícito. A Tabela 3, a seguir, mostra os resultados desta classificação: 
Tabela 3 - Classificação da posição pronominal do pronome "nós"

\begin{tabular}{c|c|c} 
Posição pronominal & Total & \% \\
\hline Anteposto & 82 & $100 \%$ \\
\hline Posposto & 0 & $0 \%$ \\
\hline TOTAL & 82 & $100 \%$
\end{tabular}

Em todas as 82 linhas de concordância analisadas (100\% dos casos) em que o pronome "nós" está explícito, ele se encontra em posição anteposta ao verbo. O resultado difere parcialmente dos obtidos por Maia (1998): enquanto na análise aqui empreendida foram encontrados unicamente casos de anteposição pronominal, os dados de Maia (1998) indicam uma predileção pela anteposição. Cumpre enfatizar, no entanto, que a pesquisa de Maia (1998) tem como foco a primeira pessoa do singular, diferentemente da pesquisa aqui realizada (focada na primeira pessoa do plural). Trabalhando tanto com textos originalmente escritos em português quanto com textos traduzidos para o português, Maia (1998) analisa as posições pronominais (do pronome "eu”) e observa uma predileção da língua portuguesa pela anteposição pronominal: em 191 linhas (64,5\% dos casos, segundo a autora), o pronome "eu" é colocado em posição anteposta ao verbo a ele associado - contra 50 linhas em que se verificam casos de posposição pronominal nos dados da autora.

Comparando os resultados sobre os usos do pronome "nós" com os usos do pronome "we", salientamos que, ao todo, foram levantadas 1.484 linhas de concordância a partir do nódulo "we". Uma possível explicação para a diferença no total de linhas de concordância levantadas em português (798, a partir das desinências associadas ao pronome "nós") e as levantadas em inglês (1.484, a partir dos usos explícitos do pronome "we") está no uso obrigatório de pronomes pessoais na língua inglesa, levando a uma reiteração mais frequente do pronome pessoal em inglês. Fenômeno semelhante acontece no corpus de Maia (1998): o pronome " $P$ " aparece com uma frequência superior ao pronome "eu" nos dados apresentados pela autora (que também trabalha, em seu corpus, com textos originalmente escritos em português e traduzidos para o inglês) - o que corrobora a explicação de que a diferença no número de linhas de concordância no corpus investigado nesta pesquisa pode se dar pela diferença sistêmica entre as línguas. 
A análise do pronome "we" em The Devil do pay in the backlands revela uma predominância pelo uso do pronome em posição anteposta ao verbo (em 96\% dos casos, o pronome antecede o verbo) - o que também pode ser atribuído à estrutura gramatical da língua inglesa (considerando que em língua inglesa, os pronomes pessoais antecedem os verbos no modo afirmativo, havendo inversões apenas em casos e modos específicos).

A seção a seguir discute o último ponto investigado a partir dos dados: a valoração associada aos pronomes "nós" e "we" e a associação desses aos processos de construção de identidades coletivas.

\subsection{O uso dos pronomes "nós" e "we" na construção de identidades coletivas}

Após uma análise quantitativa dos pronomes e suas respectivas posições no corpus bilíngue, a investigação aqui realizada passou a se concentrar na análise dos dêiticos e nas prosódias semânticas associadas aos diferentes grupos sociais construídos por meio desses. A expectativa inicial - gerada a partir de um estudo piloto dos dados - apontava para os usos dos pronomes "nós" e "we" como indicativos do estabelecimento de coesão entre grupos sociais e para a construção de uma prosódia semântica positiva associada a esses grupos.

A análise da totalidade dos dados, contudo, não corrobora a expectativa inicial, permitindo observar que os pronomes "nós" e "we" nem sempre constroem a noção de coesão social em referência a um grupo aliado nas situações de conflito construídas no corpus investigado - construindo também relações entre personagens, entre narrador e leitor e outras situações. Um exemplo em que o pronome "nós" não constrói uma identidade coletiva de um dos grupos envolvidos nos conflitos armados travados no corpus, mas de um subgrupo dentro desse grupo social está apresentado a seguir:

Ex. 5. Pensei em Diadorim. O que eu tinha de querer era que nós dois saíssemos sobrados com vida, desses todos combates, acabasse a guerra, nós dois largávamos a jagunçada, íamos embora, para os altos Gerais tão ditos, viver em grande persistência.

O Exemplo 5, acima, como anteriormente mencionado, não constrói a noção de nós em referência a todo um grupo social envolvido em uma situação de conflito, mas a um subgrupo dentro desse grupo, fazendo referência a apenas dois dos membros do grupo - no caso, o narrador Riobaldo e seu companheiro de jagunçagem Diadorim. 
Embora haja casos em que a identidade coletiva não esteja diretamente relacionada aos grupos sociais envolvidos nas situações de conflito construídas no corpus, em grande parte dos casos em que os pronomes "nós" e "we" são utilizados, a identidade coletiva construída é formada entre Riobaldo (personagem principal e também narrador) e o grupo de jagunços do qual ele faz parte. A constituição dos grupos de jagunços e as relações de aliança e de rivalidade com demais grupos, no entanto, sofrem alterações ao longo da história: havendo inicialmente um grupo liderado pelo personagem Joca Ramiro, tendo o personagem Zé Bebelo como líder do grupo inimigo, posteriormente essas relações se alteram e o grupo aliado passa a ser liderado por Zé Bebelo (antes inimigo), tendo como inimigo o grupo liderado pelo personagem Hermógenes (antes aliado).

Devido à estrutura da narrativa, tanto em inglês como em português, as alianças (e consequentemente as identidades coletivas) variam no tempo e de acordo com as circunstâncias. Os exemplos a seguir são casos em que os pronomes estão explícitos e antepostos aos verbos e nos quais os pronomes "nós" e "we" constroem referências aos grupos aliados nas situações em que os falantes se inserem. Como já dito, no entanto, a composição desses grupos sofre mudanças ao longo da narrativa, havendo referências ao grupo de jagunços liderado do personagem Joca Ramiro e ao grupo liderado pelo personagem Zé Bebelo.

Ex. 6. Para assuntar e ver com ver, o Jenolim saiu em rumo do Jequitaí, de sua LagoaGrande; e, com a mesma tenção, rebuçado viajou o Acrísio, até Porteiras e o Pontal da Barra, com todos os ouvidos bem abertos. E nós ficamos esperando a volta deles, cinco dias lá, com grande regozijo e repouso, na casa do preto Pedro Segundo de Rezende, que era posteiro em terras da Fazenda São Joãozinho, de um coronel Juca Sá.

Ex. 7. Um pelo São Lamberto, da mão direita; outro pegou o Riacho Fundo e o Córrego do Sanhar; outro se separou da gente no Só-Aqui, indo o Ribeirão da Barra; outro tomou sempre à mão esquerda, encostando ombro no São Francisco; mas nós, que vínhamos mais Zé Bebelo mesmo em capitania, rompemos, no meio, seguindo o traço do Córrego Felicidade.

Os exemplos 6 e 7 mostram, em português, situações em que o pronome "nós" referese a um grupo aliado no qual o falante está inserido. Enquanto no Exemplo 6, a referência ao grupo indica apoio ao personagem Joca Ramiro, no Exemplo 7, é mostrado um caso em que o narrador passa a pertencer ao grupo liderado por Zé Bebelo. Cumpre destacar que a identificação dos dêiticos foi realizada a partir das linhas de concordância expandidas, de modo a observar os contextos das linhas em questão.

NASCIMENTO, ALVES. O uso dos pronomes "nós" e "we" e a construção de identidades coletivas no corpus paralelo Grande Sertão: Veredas || The Devil to Pay in the Backlands.

Belas Infiéis, v. 6, n. 1, p. 43-64, 2017. 
Na língua inglesa, semelhante mudança de alianças ocorre. Nos exemplos 8 e 9, a seguir, são apresentados casos em que o pronome "we" é utilizado em situação de conflito:

Ex. 8. After that rest, we would move out from there, under the command of Medeiro Vaz, and go after those others -- after them! There was no lack of ammunition. We numbered sixty men -- all cabras of the very best.

Ex. 9. And then Marcelino Pampa and his men also came on the scene, appearing unexpectedly, to the greater distress of the Hermógenes. It was a slaughter. We caught the enemy in a cross fire.

O exemplo 8 nos mostra um caso em que o grupo aliado pertence ao grupo de Medeiro Vaz, que se encontra em confronto com o grupo de Zé Bebelo. O narrador encontra-se em situação de conflito e o "we" se refere ao bando do qual o mesmo faz parte. A prosódia semântica aqui encontrada é neutra, pois trata-se de uma fragmentação do grupo. No exemplo 9 o grupo hostil passa a ser o grupo de Hermógenes. Neste caso, observamos uma prosódia semântica positiva, onde o grupo encontra-se em conflito, em posição de liderança em ataque ao inimigo. Em ambos os casos, o pronome se encontra na posição anteposta ao verbo e se 60 refere ao grupo aliado em conflito com o grupo hostil.

Quando isolados apenas os casos em que a noção de nós constrói a identidade coletiva de um dos grupos envolvidos nos conflitos armados travados, a análise da totalidade dos dados também não confirmou as expectativas em torno da prosódia semântica associada aos grupos. Um estudo piloto realizado a partir do corpus indicava a associação de características proeminentemente positivas aos grupos sociais identificados por meio dos pronomes "nós" e "we" - indicando semelhanças entre os dados do corpus a ser até então analisado e o estudo de Leudar, Marsland e Nekvapil (2004) acerca da categorização nós versus eles em um discurso político. Ressaltamos que, embora o corpus aqui analisado tenha características genéricas diferentes das do corpus de Leudar, Marsland e Nekvapil (2004), a comparação entre as análises parte da ideia de que corpora de pequenas dimensões permitem ao(à) analista visualizar questões maiores, associáveis ao sistema linguístico, como ressalta Sinclair (2001), ou trabalhar a noção de texto como janela para o sistema, como apontam Halliday e Matthiessen (2004). 
Diferentemente do "nós" analisado por Leudar, Marsland e Nekvapil (2004) - ao qual são atribuídas características majoritariamente positivas - a noção de "nós" (enquanto grupo social) no corpus aqui investigado também é construído com prosódias semânticas neutras e negativas, como mostram os exemplos a seguir:

Ex. 10. Se ia, o pesadelo. Pesadelo mesmo, de delírios. Os cavalos gemiam descrença. Já pouco forneciam. E nós estávamos perdidos. Nenhum poço não se achava.

Ex. 11. Daí a cinco madrugadas, retornamos.

Os Exemplos 10 e 11 mostram, respectivamente, uma situação em que o grupo social identificado como nós se encontra em um estado de desolamento, com referências simbólicas a pesadelos, gemidos e descrença - construções linguísticas que constroem uma prosódia semântica negativa em torno do grupo aliado. Já o exemplo 11 mostra uma valoração neutra, na qual o grupo representado pela ideia de nós (elíptico no verbo "retornamos") indica apenas uma situação de movimento do grupo, sem construir uma prosódia negativa, nem positiva.

Assim sendo, é possível dizer que a análise das construções sociais a partir dos pronomes dêiticos "nós" e "we" no corpus aqui analisado indica construções mais fluidas dos grupos sociais - com mudanças de posições, alinhamentos e alianças -, também marcadas por um não maniqueísmo, havendo inclusive a atribuição de características negativas ao grupo construído como aliado.

Por fim, a seção a seguir apresenta considerações que podem ser tecidas a partir da análise dos dados e das principais discussões feitas neste artigo, retomando pontos relevantes e possibilidades de futuras pesquisas e desenvolvimentos que podem ser empreendidos a partir deste trabalho.

\section{Considerações finais}

Este artigo se propôs a apresentar um recorte de uma pesquisa acerca dos usos dos pronomes "nós" e "we", quando colocados em relação de tradução, e acerca da forma como esses pronomes marcam o estabelecimento de uma coesão entre indivíduos e a consequente formação de uma identidade coletiva, em uma situação de conflito armado, travado entre grupos sociais em um corpus paralelo ficcional.

NASCIMENTO, ALVES. O uso dos pronomes "nós" e "we" e a construção de identidades coletivas no corpus paralelo Grande Sertão: Veredas || The Devil to Pay in the Backlands.

Belas Infiéis, v. 6, n. 1, p. 43-64, 2017. 
Dentre os resultados observados a partir da análise aqui empreendida, destacam-se a tendência da língua portuguesa pela elipse pronominal e pela anteposição do pronome em relação ao verbo (quando esse pronome está explícito nas orações). Em língua inglesa, também foi verificada uma tendência pela anteposição pronominal - o resultado, no entanto, é mais associável à estrutura da língua do que a possíveis escolhas de tradução.

Ao analisar a dêixis dos pronomes "nós" e "we", a pesquisa indica que as construções sociais representadas por esses pronomes são fluídas, não havendo um maniqueísmo no tratamento dos grupos - e ocorrendo, inclusive, a atribuição de características negativas ao grupo construído como aliado.

Como vantagens de pesquisas como a aqui apresentada, ressaltamos não apenas a importância da comparação de sistemas linguísticos para a análise de textos, como também a possibilidade de uso dessas comparações para a exploração (e/ou o aprendizado) de línguas estrangeiras. Seguindo o exemplo de Pagano e Figueredo (2011) - que também apresentam uma pesquisa baseada em corpora para comparar sistemas linguísticos -, entendemos como salutar comparar os recursos linguísticos que a língua materna e uma língua estrangeira

62 oferecem para construir significados, uma vez que tal comparação possibilita pensar a gramática de forma comparada, observar como significados são construídos com base nas frequências de ocorrência num corpus e promover a reflexão sobre a linguagem.

Como futuros desdobramentos deste trabalho, uma indicação aponta para a investigação de estudos da construção de indivíduos frente aos grupos colocados em relação de conflitos, analisando, por exemplo, a partir dos usos do pronome "eu" no corpus Grande Sertão: Veredas como o indivíduo, em sua particularidade, se comporta diante de uma situação de conflito e perante os diferentes grupos sociais (aliados e hostis) que o circundam.

\section{REFERÊNCIAS BIBLIOGRÁFICAS}

ALVES, D. Conflito e tradução: Uma análise sobre as realizações linguísticas dos conflitos armados entre grupos litigantes no corpus paralelo Grande Sertão: Veredas - The Devil to Pay in the Backlands. Tese (doutorado). Universidade Federal de Santa Catarina, 2014. Disponível em: http://goo.gl/q1B9R7. Último acesso em 23/04/2015.

ALVES, D.; ASSIS, R. C. Métodos de investigação em corpora: Ferramentas para classificação de dados extraídos de corpora de pequenas dimensões para análises discursivas. VIII Escola Brasileira de Linguística Computacional \& XIII Encontro de Linguística de Corpus, Blucher Social Sciences Proceedings, Volume 2, 2016, p. 1-17. Disponível em: https://goo.gl/7GV7o2. Último acesso em 04/11/2016. 
ANTHONY, L. AntConc 3.2.4w. Tokyo, Japão: Waseda University, 2011. Disponível em: http://goo.gl/3GVS. Último acesso em 04/01/2012.

AZEREDO, J. C. Fundamentos de Gramática do Português. 5. ed. Rio de Janeiro: Zahar, 2010.

BAKER, M. Translation and conflict: a narrative account. New York: Routledge, 2006.

BARBARA, L. e GOUVEIA, C. It is not there, but [it] is cohesive: the case of pronominal ellipsis of subject in Portuguese. In: BANKS, D. (ed.). Text and Texture: Systemic Functional viewpoints on the nature and structure of text. 2004, Paris: L'Harmattan, p. 159172. Disponível em: http://goo.gl/JE7sPO. Último acesso em 27/07/2016.

BAR-TAL, D. Introduction. In: BAR-TAL, D. (Ed.). Intergroup conflicts and their resolution: Social psychological perspective. New York: Psychology Press, 2011.

BREWER, M. B. Identity and conflict. In: BAR-TAL, D. (Ed.). Intergroup conflicts and their resolution: Social psychological perspective. New York: Psychology Press, 2011.

BIRNBAUM, Pierre. Conflitos. In: BOUDON, R. et al. Tratado de Sociologia. Rio de Janeiro: Jorge Zahar, 1995. Disponível em: http://goo.gl/tGZm9. Último acesso em 20/01/2012.

BUTT, D. G.; LUKIN, A.; MATTHIESSEN, C. M. I. M. Grammar - the first covert operation of war. In: Discourse \& Society. London: Sage publications, 2004, vol. 15(2-3), p. 267-90.

HALLIDAY, M.A.K.; MATTHIESSEN, C. M. I. M. An Introduction to Functional Grammar. London: Oxford University Press, 2004.

LEUDAR, I.; MARSLAND, V.; e NEKVAPIL, J. On membership categorization: 'us', 'them', and 'doing violence' in political discourse. Discourse \& Society. London: Sage publications, 2004. Disponível em: https://goo.gl/JpVQYq. Último acesso em 09/08/2016.

MAIA, B. Word Order and the First Person Singular in Portuguese and English. In: Meta: journal des traducteurs / Meta: Translators' Journal, vol.43, n4, 1998. Disponível em: http://goo.gl/SfzC2F. Último acesso em 09/08/2016.

PAGANO, A. S. e FIGUEREDO, G. P. 'Gramaticalização da dor em português e espanhol: uma abordagem comparada com subsídios da linguística de corpus e da linguística sistêmicofuncional'. In: VIANA, Vandes \& TAGNIN, Stella E.O, Corpora no ensino de línguas estrangeiras. São Paulo, HUB Editorial, 2011

PEDROSA, M. F. A visibilidade do tradutor. [Blog Marcos Pedrosa de Souza] Rio de Janeiro, 15 de janeiro de 2009 [. Disponível em: http://goo.gl/Ecdx85. Último acesso em 10/07/2016. 
SILVA, F.; VASCONCELLOS, M. L. B.; FERNANDES, L. P. Semantic prosody and collocational profile in "The black cat" and "O gato preto". In: X Encontro Nacional de Tradutores / IV Encontro Internacional de Tradutores, 2009, Ouro Preto. Anais do X Encontro Nacional de Tradutores \& IV Encontro Internacional de Tradutores da ABRAPT. 2009, p. $974-992$.

SINCLAIR, J. M. Preface. In: GHADESSY, Mohsen; HENRY, Alex; ROSEBERRY. R. L. Small Corpus Studies and ELT: Theory and practice. Amsterdam/Philadelphia: John Benjamins Publishing Company, 2001, xi.

VASCONCELOS, S. G. T. João \& Harriet (Notas sobre um diálogo intercultural). In: CHIAPPINI, Ligia; VEJMELKA, Marcel (org.). Espaços e caminhos de João Guimarães Rosa: dimensões regionais e universalidade. Rio de Janeiro: Ed. Nova Fronteira, 2009, p.7381.

RECEBIDO EM: 09/11/2016

ACEITO EM: 01/12/2017

PUBLICADO EM: junho de 2017

${ }^{1}$ Cristiane Bezerra do NASCIMENTO - Bacharel em Direito (2010) pelo Centro Universitário de João Pessoa UNIPÊ. Atualmente é discente do Bacharelado em Tradução na Universidade Federal da Paraíba (UFPB). João Pessoa, Paraíba, Brasil.

Lattes: http://lattes.cnpq.br/9821738679263362 E-mail: cristianebz@ hotmail.com

${ }^{2}$ Daniel Antonio de Sousa ALVES - Graduado em Letras (2003) e Mestre em Estudos Linguísticos (2006) pela Universidade Federal de Minas Gerais (UFMG). Doutor em Estudos da Tradução (2014) pela Universidade Federal de Santa Catarina (UFSC). É professor adjunto da Universidade Federal da Paraíba (UFPB) no bacharelado em Tradução. João Pessoa, Paraíba, Brasil.

Lattes: http://lattes.cnpq.br/5099347989756580 E-mail: daniel.alves.ufpb@gmail.com

${ }^{3}$ Ao longo deste artigo, o uso de itálico nas palavras nós, we e eles indica que a discussão diz respeito aos grupos sociais cuja formação está implícita nessas palavras. A marcação visa a diferenciar as referências a essas palavras quando são usadas como referências diretas aos pronomes pessoais (marcadas pelo uso de aspas, como em "nós" e "we") 